\title{
The Effect of Assimilating Learning Management Systems on Parent Involvement in Education
}

\author{
Roman Yavich ${ }^{1, *} \&$ Nitza Davidovitch ${ }^{1}$ \\ ${ }^{1}$ Ariel University, Ariel, Israel \\ *Correspondence: Ariel University, Ariel, Israel. E-mail: romany@ariel.ac.il
}

Received: March 3, 2021

Accepted: May 21, $2021 \quad$ Online Published: June 16, 2021

doi:10.5430/wje.v11n3p60

URL: https://doi.org/10.5430/wje.v11n3p60

\begin{abstract}
In recent years a new culture of online interactivity and pedagogic management through learning management systems has been gradually acquiring force, in addition to the traditional culture of face-to-face interactions as well as use of other media. Although much research work has been done in recent years on the significance of parent involvement in the educational process, no thorough research has been conducted on the effect of exposure to learning management systems that offer students and their parents maximal transparency of the educational environment, including the level of communication between the student's parents and the teaching staff and their level of involvement in the educational process, particularly in the current period during the outbreak of the coronavirus crisis that has forced the educational system and other routine systems to switch to an online sphere against their will.

The current work examined the effect of assimilating an online learning management system, the Mashov system (a Hebrew acronym for immediacy, transparency, and monitoring) on parent involvement in their children's educational process. The significance of the research topic is particularly evident in these uncertain times, when the traditional learning environment is being compelled to make way for distance learning due to the outbreak of the coronavirus crisis, assisted by learning management systems and primarily the Mashov system. Therefore, there is room to enhance research in this field throughout the crisis and, once it is over, in further valuable studies.
\end{abstract}

Keywords: learning management system, parent involvement, technology integration, Mashov system, LMS

\section{Introduction}

In recent years, with the development of internet technologies, use of new communication channels between educational facilities and parents has also grown (Blau \& Hameiri, 2012). Applications such as electronic mail, social networks, instant messaging, school information and communication systems (such as the Mashov system, to be expanded below), and mobile media such as smartphones, have the potential of enhancing parent involvement in their children's educational process (Kaplan Toren, 2004).

\subsection{Parent Involvement in the Educational Process}

Parents and teachers have major significance in students' developmental and educational process, in which they are expected to acquire values, education, and behavior norms. Moreover, parent involvement contributes both to students' social adjustment and to their academic achievements (Neal, 2012). Many studies on parent involvement in the traditional educational system (Hango, 2007) note its impact on diverse aspects of their children's functioning. Parent involvement has a positive effect on students' achievements when the parents discuss matters pertaining to the school with their children and attend events at the school. Nonetheless, no positive effect was found of parents' checking their children's homework or expressing opinions on the children's friends, and in some cases, this was even found to have a negative effect on achievements.

The influence of parent involvement was also examined among mothers and fathers of teens, finding that the interest expressed by parents of 16-year-old boys in occurrences at their school has a considerable and long-term impact on their children's future education. Moreover, fathers' interest in occurrences at the school was found to be particularly important and may even reduce the negative impact of low socioeconomic status on their children's future education 
(Hango, 2007). Moreover, it is evident from the research that such interest is efficient only if it occurs over time, while parent involvement only in the event of a problem at the educational facility is associated with low self-esteem of adolescents with regard to their functioning at school (Kaplan Toren, 2004).

\subsection{Parent-teacher Communication}

Communication between parents and teachers requires sharing information pertaining to the child from the two environments that he frequents: the educational environment and the family environment. At present, parent-teacher communication means direct and bilateral contact between the sides, based on a system of conveying messages (face-to-face meetings, telephone conversations, and new communication channels supported by computers and cellular devices). In this communication, the school staff provide the parents with information about the school policy, customary methods of evaluation, various programs, and the social and educational progress of the students. At the same time, the school is supposed to receive information from the student's parents, his needs, unique features, and the parents' preferences regarding their children's education (Shechtman \& Bushrian, 2015).

\subsection{Integrating Technology in Parent-teacher Communication}

Parent involvement is optimal when there is regular and efficient communication with the teaching staff (Hoover-Dempsey, Whitaker \& Ice, 2010). In recent years, with the expansion of new communication and information technologies, the use of these communication channels between parents and teachers has increased. Effective communication between parents and teachers requires participation of both sides in the educational process. At the same time, there is no doubt that the responsibility for the success of this communication rests mainly on teachers, who are responsible for forming initial contact with the parents and encouraging their involvement both in school activities and in their children's learning process (Shechtman \& Bushrian, 2015).

\subsection{Online Learning Management Systems}

Learning management is mostly directed by academic goals. Management of this type is based on data derived from all aspects related to the learning system (Maciariello, (2018)). In recent years, online learning management systems have become an essential tool for effective data-based management. Decision makers in the various schools examine online systems by their ability to help them manage the student's data interface, which enables updating of and following by all those involved in the student's educational process, while effectively assimilating innovative interaction channels among the school staff (Cameron \& Mahoney, 2008).

The most conspicuous system in this area in Israel is the Mashov system (a Hebrew acronym for immediacy, transparency, and monitoring), which provides pedagogic management services by means of an online support system utilized in schools within the educational system. Through the Mashov system the school teaching staff manages the database that includes the student's file, notes on behavior (in class and outside), grades on recent assignments and exams, and information on classroom attendance. The Mashov system was developed with the aim of utilizing the computer and internet infrastructure for purposes of reporting, processing, and using relevant data in real time, in order to enhance the school's administration. The educational system encourages use of the Mashov system, which utilizes the school-based database (Blau \& Hameiri, 2011). The various platforms for accessing the system are based on internet access: via PC, tablet, or smartphone. Moreover, the school teaching staff can define important parameters for monitoring, including data concerning the student's functioning, grades, study contents, homework, academic adaptations, placement in tracks and subjects, communication, and so on. The data is entered and distributed among the parents in real time and makes it possible to update all those involved (the educational staff, the parents, and the child) with relevant information at any given moment, in the form of legible and accessible reports. For instance, when following classroom attendance, once data on students' classroom attendance is entered in the program all the partners noted will receive notice: the homeroom teacher receives an overall picture of the class, while the parents receive information about their child (Shechtman \& Bushrian, 2015).

In order to form an optimal match, the Mashov system includes two components: a teachers' Mashov, through which all the interactions among the teachers' staff take place in a closed circuit, and a students' and parents' Mashov that enables access by students and their parents to the student's data and facilitates communication between the students' families and the teacher staff (see Figure 1). 


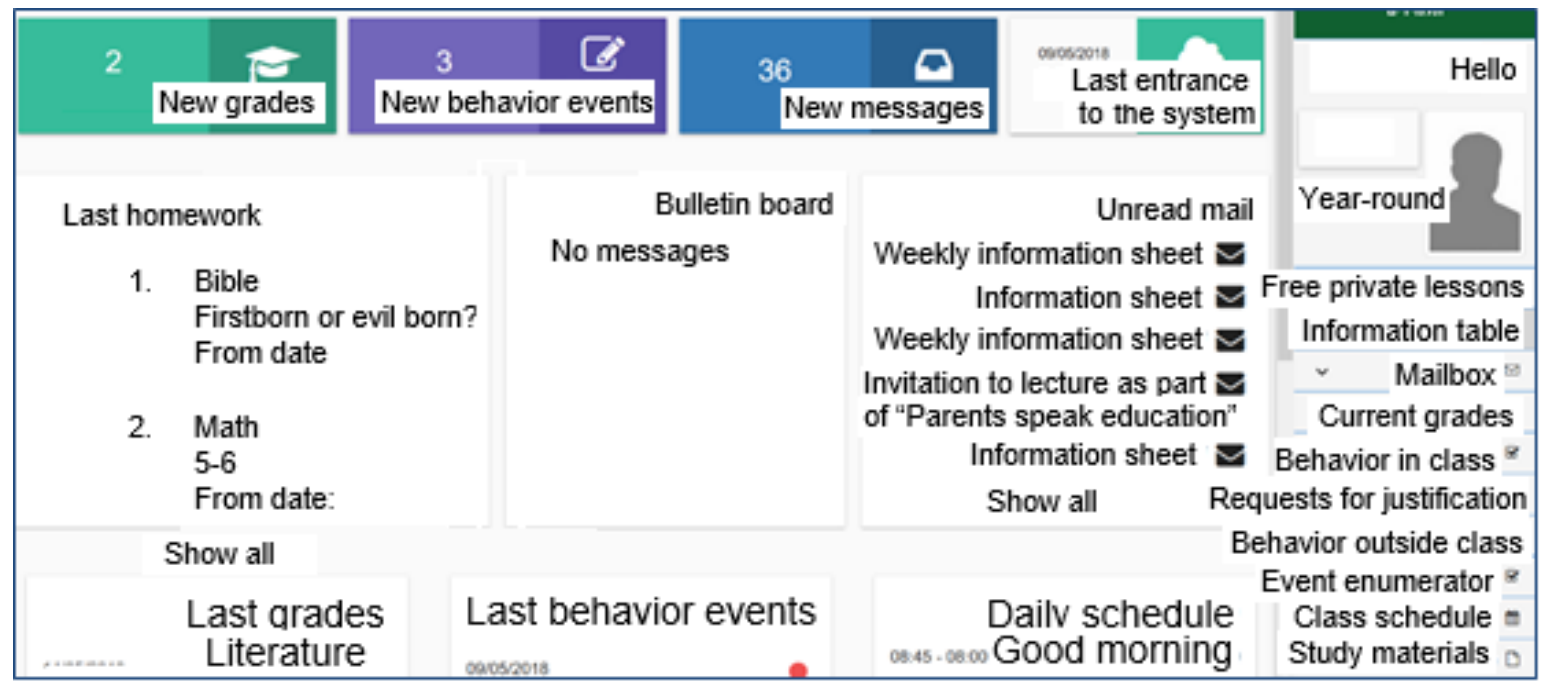

Figure 1. Mashov System Information Table for Students and Parents

Studies conducted on use of the system indicate differences between students and parents. In a longitudinal study conducted over three years (Blau \& Hameiri, 2011), the researchers found that the frequency of student use is strongly affected by the amount of information updates by the teaching staff. The study found that the number of students who persevered and continued to access the online system throughout all three years of the study was 3.5 times higher among students of teachers who entered multiple daily data than among students of teachers who entered little data (Blau \& Hameiri, 2011).

A follow-up study (Blau \& Hameiri, 2012) found that the activity scope of students and parents is also associated with the frequency of data update by the teacher. The researchers detected that multiple entering of data in the system by teaching staff increased the interactivity among families and led to a rise in the amount of system accessing by students, mothers, and fathers. At the same time, similar to previous studies on parent involvement in the traditional environment, the current study too found gender-related differences in patterns of parent involvement. Mothers entered the online system twice as often as fathers, embraced the technology more rapidly, and were also more capable of utilizing teachers' readiness to make an effort to enter data daily in order to receive updates on their children's progress (Blau \& Hameiri, 2012). These studies and others lead to the conclusion that the Mashov system facilitates actual communication between parents, teachers, and students. Communication is based on reports by the teaching staff concerning the student in the digital system, among other things on grades and attendance.

Studies conducted on the frequency of using the Mashov system (Blau \& Hameiri, 2012) found a very high frequency of student entrances to the system, indicating students' wish to receive regular updates on information posted by teaching staff about their studies. In contrast, parents accessed the system relatively infrequently, and they showed an unequivocal preference for e-mail communication over communication by means of the Mashov system. Parents may prefer to receive classroom notices and personal notices directly to their e-mail because this action provides them with direct access to the information instead of having to actively enter the system to receive updates.

Side by side with all the advantages, the Mashov system also has several weaknesses: As part of their functioning in the educational system, children aspire to reach gradual independence and a sense of autonomy as mature individuals, while use of this system might generate hesitation by adolescents who might interpret it as intruding on their privacy and compromising it and thus causing conflicts with their parents. Another weakness is the difficulty of the Mashov system to detect achievements as well as difficulties on the school, grade, class, and student level, compared to interpersonal communication. Indeed, use of the system by teaching staff facilitates easy and lengthy monitoring and includes reaching conclusions concerning necessary changes in teaching methods, identifying academic needs for further support, etc., however the very use of the system as a tool for communication between teaching staff and students, as well as between parents and teachers, might detract from a foundation built over many decades.

\subsubsection{Assimilating Learning Management Systems in Schools}

In the last three decades, a process of assimilating learning management systems (LMS) in the various schools has begun. A study examining how educational technologies are assimilated presented two main models. In the first 
model, called "Islands of innovation", the assimilation process was described as focusing on a content area or defined task, and as taking place only within part of the educational organization rather than leading to an essential change in the organizational culture (Forkosh-Baruch, Nachmias, Mioduser \& Tubin, 2005). In contrast the second model, called "Comprehensive innovation", describes an assimilation process that takes place at all levels of the educational organization and is also capable of generating a new organizational culture (Forkosh-Baruch et al., 2005).

In a study conducted in ten secondary schools (Blau \& Hameiri, 2012), the researchers sought to examine how the Mashov learning management system is assimilated, based on the models described above. The research findings revealed that seven of the ten schools embraced assimilation of the comprehensive innovation model and included in the technological assimilation process both the students and their parents, their natural partners in managing the learning system. Nevertheless, assimilation of new technologies in schools resembles assimilation of various technologies in all life systems, which depends first and foremost on the readiness of those in the environment to accept the change and embrace it.

Over the years, many researchers have attempted to examine the individual's readiness to embrace change or innovation, headed by sociologist Rogers (1995) who classified individuals by their readiness to embrace change: The first, whom he called the "innovators", are willing to take a risk and try new things and therefore they are the first to embrace innovations even when they are foreign to them. The second to embrace innovations are the "early adopters", whom Rogers (1995) identified as public opinion leaders. These are closely followed by the "early majority", who tend to embrace innovations however only with the support of the "early embracers", whose actions they follow religiously. The individuals ranked fourth are the "late majority", considered more suspicious of innovations and who therefore tend to embrace them later than the others. The fifth and last group were designated by Rogers (1995) the "laggards", because they are often intimidated by innovations and take their time adopting them.

\subsubsection{Maximal Assimilation of the Mashov System in Conditions of Distance Learning (the COVID-19 crisis)}

Although the Mashov system was intended to serve as an interactive communication channel in the planning stage (Blau \& Hameiri, 2012), in practice only when the COVID-19 crisis emerged in Israel in early 2020, a crisis that required distance learning methods in order to continue the study routine under limitations of social distancing, was the Mashov system truly tested: Many functions were added to the system as needed, including the "online classroom" (in order to hold online classes and even online parent-teacher meetings). Moreover, when use of the Mashov system was enhanced as part of distance learning, data on student attendance of online lessons were updated (see Figure 2) and study material for use when connecting from home was added, as well as a dynamic schedule and a list of homework that can be submitted directly to the teacher's designated e-mail through the system.

\subsubsection{Teachers' Attitudes towards Assimilating Learning Management Systems}

There is no question that assimilating learning management systems in the educational environment requires active involvement by the educational staff. The attitudes of teachers towards learning systems and their assimilation might have a considerable impact on the optimal implementation of these systems or their abject failure. Therefore, it is necessary to enable accompaniment and guidance in working with these innovative learning systems also for teachers and homeroom teachers.

One example is a study that examined how the Mashov system is assimilated in a high school (Timan, 2007), based on self-report by teachers who had been exposed to the system for the first time and received structured guidance on it. The research findings (Yavich, 2013) revealed that the teaching staff who participated in the study perceived the Mashov system as an environment that promotes interaction within the teachers' staff and improves pedagogical-organizational conduct, and therefore saw the significance of increasing interactions with students and families while familiarizing them with the system and accompanying them in guidance processes so that they would adopt it optimally. Moreover, a study conducted among high schools and junior highs that utilized the Mashov system versus similar schools that made no use of an information management system (Davidovich \& Yavich, 2015; Davidovich \& Yavich, 2017) found a significantly higher rate of parent involvement in the educational process in schools that used the Mashov system than in schools that had not assimilated the Mashov system or other parallel systems.

To summarize the literature review, despite the innovativeness of new communication channels between the educational staff and the parents and their many benefits, it must be emphasized that the continued existence of face-to-face communication channels, including personal conversations initiated by parents or teachers and 
parent-teacher meetings during the school year, are irreplaceable. These encounters facilitate close contact and form trust and professional work relations between parents and teachers. Most of the studies see the entrance of new communication channels positively and as intended to increase parent involvement, but certainly not as a replacement for face-to-face communication. Information sharing systems such as the Mashov system contribute to parent involvement in the school's work, and are perceived as having a positive impact on progress in the students' learning, including achieving high grades. A major component of involvement is the frequency of communication between parents and teachers and its intensiveness. Therefore, use of new communication technologies creates new opportunities for communication between parents and teachers due to increasing parents' access to the teacher. Nevertheless, the high accessibility might lead to an increased mental burden on the teacher who must respond to a large amount of messages from all the parents.

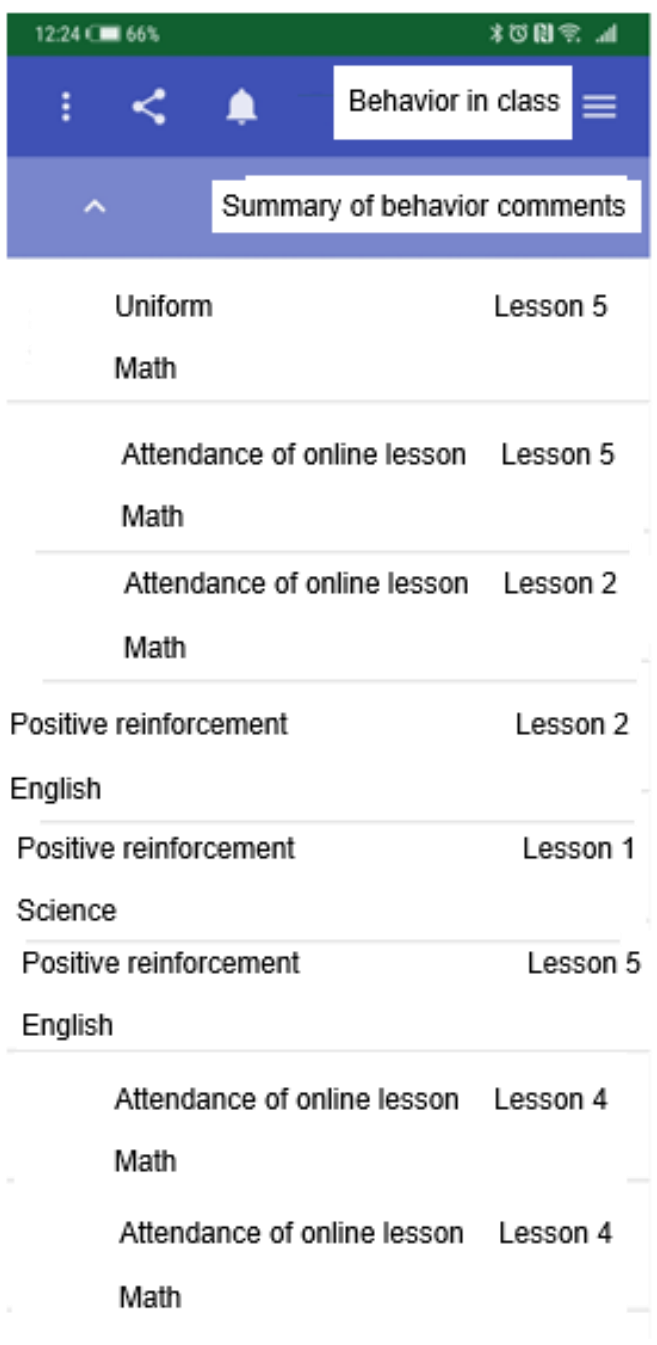

Group 3 - Wednesday
Start date
End date
Class opened by Bechor Meitall Ial
Letters
Start date
End date

Figure 2. Adapting the Mashov System During COVID-19 - the Online Classroom and Behavior in an Online Lesson

Successive use of the Mashov system is expected to lead to improved teacher-parent communication and greater involvement by both sides in the educational process, but it is important not to blur the boundaries between the home environment and the private environment (maintaining the privacy of all those involved on one hand, including the student himself, and respect for the teacher's personal time outside the school setting). Therefore, in outstanding cases where maintaining the student's privacy is very significant, there may be room to better balance use of the system: for instance, information related to academic achievements and the student's attendance will reach the 
parents mediated by the adolescent rather than directly, so that the student will have an opportunity to prepare for the conversation with the parents and also know in advance what information is involved.

The current study examined the effect of assimilating the Mashov system on parent involvement in the educational process of their children. The research question was: How does assimilation of the Mashov system affect parent involvement in their children's educational process? The next chapter will present the research rationale as well as the research hypotheses that will be examined in the study.

\section{Research Rationale and Research Hypotheses}

\subsection{Research Rationale}

The research literature indicates that parent involvement in the educational process is essential for proper development of the student in the learning environment. In addition to mutual communication between the teaching staff and the parents, the students will also perceive the learning environment as a safe environment for themselves. With the many transformations decreed for the traditional learning environment by the contemporary technological era, it is appropriate to address the impact of assimilating a learning management system on parent involvement in education and its dependency on communication among all those involved in the educational process who are affected by the new circumstances.

\subsection{Research Hypotheses}

1. The greater the use of the learning management system as reported by parents, the higher their self-reported sense of involvement in their children's educational process.

2. Parents will report better communication with the teaching staff the greater their self-reported use of the learning management system.

3. Parents with children in junior high and high school will report greater use of the learning management system than parents with children in elementary school.

\section{Research Method}

This study examined the effect of assimilating a learning management system, the Mashov system, on parents' involvement in their children's educational process.

\subsection{Research Population}

The study was conducted among 132 parents of children studying at schools in Israel that use the Mashov system operated in conjunction with their child's school. The demographic characteristics of the research population are noted in Table 1.

\subsection{Research Procedure}

An online questionnaire was distributed among the research participants, sent at first to the author's close circle in her study environment and work environment, through common WhatsApp groups. Then, the questionnaire was passed on to other potential respondents in the snowball method, via e-mail and WhatsApp. The research procedure took several months, as it depended on a routine schedule in order to examine the research hypotheses, a routine that was undermined for several months due to the COVID-19 crisis in Israel.

\subsection{Research Tools}

The study utilized a questionnaire examining parents' use patterns of the online system for sharing information by the school, i.e., the Mashov system, as well as their level of involvement in their children's educational process, based on the Parent Involvement Questionnaire (Perry \& Shine, 2015).

\subsubsection{Reliability}

Examination of the research questionnaire's internal consistency found a Cronbach's alpha measure of 0.709 (by gender: 0.709 for men, 0.715 for women). The questionnaire is attached as an appendix to the study.

The next chapter will present the research findings in detail, including the statistical associations between the research variables and examination of the research hypotheses, with regard to the findings.

The questionnaire includes two parts: 
Part A - Background questions: Includes several questions on the respondents' demographic characteristics.

Part B - Parent Involvement Questionnaire: Includes 6 statements on parent involvement in their children's educational process.

In this part the respondents were asked to mark their degree of agreement with the statements on a 5-point Likert scale, where 1 - strongly disagree, and 5 - strongly agree.

Table 1. Demographic Characteristics of the Research Respondents

\begin{tabular}{|c|c|c|c|}
\hline & Men & Women & Entire sample \\
\hline No. of respondents & $(49.2 \%) 65$ & $(50.8 \%) 67$ & $(100 \%) 132$ \\
\hline \multicolumn{4}{|l|}{ Marital status: } \\
\hline Single & $(0 \%) 0$ & $(0 \%) 0$ & $(0 \%) 0$ \\
\hline Married & $(64.6 \%) 42$ & (71.6\%) 48 & $(68.2 \%) 90$ \\
\hline Divorced & $(35.4 \%) 23$ & (28.4\%) 19 & $(31.8 \%) 42$ \\
\hline Widow/er & $(0 \%) 0$ & $(0 \%) 0$ & $(0 \%) 0$ \\
\hline \multicolumn{4}{|l|}{ Education: } \\
\hline High school & $(9.2 \%) 6$ & $(14.6 \%) 10$ & $(12.1 \%) 16$ \\
\hline Bachelor's degree & $(69.2 \%) 45$ & $(53.7 \%) 36$ & $(61.4 \%) 81$ \\
\hline Graduate degree & $(21.5 \%) 14$ & $(31.3 \%) 21$ & $(26.5 \%) 35$ \\
\hline \multicolumn{4}{|l|}{ Employment: } \\
\hline Not employed & $(4.6 \%) 3$ & $(3 \%) 2$ & $(3.8 \%) 5$ \\
\hline Employed part time & $(41.5 \%) 27$ & $(40.3 \%) 27$ & $(40.9 \%) 54$ \\
\hline Employed full time & $(53.8 \%) 35$ & $(56.7 \%) 38$ & $(55.3 \%) 73$ \\
\hline \multicolumn{4}{|l|}{ No. of school-aged children } \\
\hline One child & $(13.8 \%) 9$ & $(9 \%) 6$ & $(11.4 \%) 15$ \\
\hline 2 children & $(29.2 \%) 19$ & (34.3\%) 23 & $(31.8 \%) 42$ \\
\hline 3 children & $(40 \%) 26$ & $(40.3 \%) 27$ & $(40.2 \%) 53$ \\
\hline 4 children & $(16.9 \%) 11$ & $(16.4 \%) 11$ & $(16.7 \%) 22$ \\
\hline \multicolumn{4}{|l|}{ School of eldest child } \\
\hline Elementary school & $(16.9 \%) 11$ & $(14.9 \%) 10$ & $(15.9 \%) 21$ \\
\hline Junior high & $(38.5 \%) 25$ & $(41.8 \%) 28$ & $(40.2 \%) 53$ \\
\hline High school & $(44.6 \%) 29$ & $(43.3 \%) 29$ & $(43.9 \%) 58$ \\
\hline \multicolumn{4}{|l|}{ Frequency of Mashov system use } \\
\hline Once a month & $(0 \%) 0$ & $(0 \%) 0$ & $(0 \%) 0$ \\
\hline Once every two weeks & $(1.5 \%) 1$ & $(1.5 \%) 1$ & $(1.5 \%) 2$ \\
\hline Once a week & $(43.1 \%) 28$ & $(46.3 \%) 31$ & (44.7\%) 59 \\
\hline Once a day & $(55.4 \%) 36$ & $(52.2 \%) 35$ & $(53.8 \%) 71$ \\
\hline \multicolumn{4}{|l|}{ Most useful information in the Mashov system } \\
\hline Student attendance data & $(13.8 \%) 9$ & $(11.9 \%) 8$ & $(12.9 \%) 17$ \\
\hline Student grades & $(21.5 \%) 14$ & $(20.9 \%) 14$ & $(21.2 \%) 28$ \\
\hline Behavior notes & $(24.6 \%) 16$ & $(23.9 \%) 16$ & $(24.2 \%) 32$ \\
\hline Regular announcements by the Ministry of Education & $(32.3 \%) 21$ & $(35.8 \%) 24$ & $(34.1 \%) 45$ \\
\hline Schedule and homework updates & $(7.7 \%) 5$ & $(7.5 \%) 5$ & $(7.6 \%) 10$ \\
\hline
\end{tabular}

\subsection{Data Analysis}

Data analysis was conducted with the SPSS statistical software.

\section{Findings}

For the readers' convenience, we have summarized the research variables in Table 2. 
Table 2. Research Variables Matrix

\begin{tabular}{lcc}
\hline Variable & Parent involvement in education & Communication with the teaching staff \\
\hline Parent involvement in education & & \\
Communication with the teaching staff & $0.261^{* *}$ & $0.284^{* *}$ \\
Use of the Mashov system & $0.373^{* *}$ & \\
\hline
\end{tabular}

Notes: ${ }^{*} p<0.05,{ }^{* *} p<0.01$

\subsection{Exploring the Research Hypothesis}

When examining the first research hypothesis, whereby the greater the use of the learning management system as reported by parents, the higher their self-reported sense of involvement in their children's educational process, a significant positive correlation was found between use of the Mashov system as reported by parents and their sense of involvement in the educational process $(\mathrm{r}=0.373, \mathrm{p}=0.000)$.

Moreover, when examining respondents' agreement with the sixth statement in the questionnaire whereby use of the Mashov system affects the sense of involvement in the educational process, most of the research respondents (about $98 \%$ ) agreed or strongly agreed with the statement, as follows (Figure 3):

\section{I feel that use of the Mashov system affects my involvement in my children's educational process}

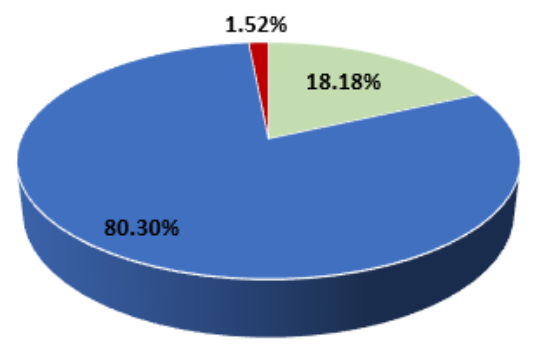

\section{Neutral -Agree' Strongly agree}

Figure 3. The Effect of Use of the Mashov System on the Sense of Involvement in the Educational Process

When examining the second research hypothesis, whereby parents will report better communication with the teaching staff the greater their self-reported use of the learning management system, a significant positive correlation was found between use of the Mashov system as reported by the parents and their level of communication with the teaching staff $(r=0.284, \mathrm{p}=0.001)$.

Moreover, when examining respondents' degree of agreement with the fifth statement in the questionnaire whereby the level of communication with the teaching staff is based on respondents' use of a learning management system (the Mashov system) (Figure 4), most of the research respondents (about 92\%) were found to agree or strongly agree with the statement, as follows: 


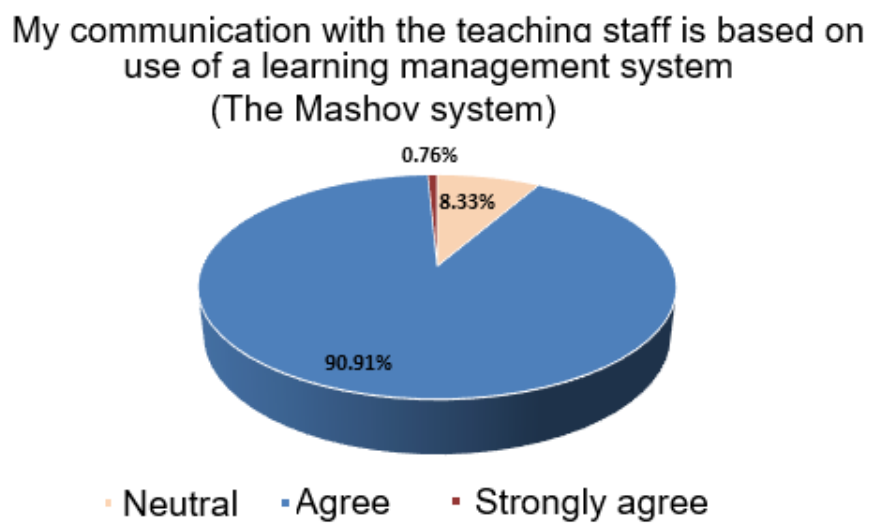

Figure 4. Level of Communication with the Teaching Staff Through the Mashov

When examining the third research hypothesis, whereby parents with children in junior high school and high school will report greater use of the learning management system than parents with children in elementary school, the difference between the usage levels reported by parents of children in the different schools (elementary school, junior high, and high school) was reported by a t-test for independent samples.

The test was conducted twice. The first time, the difference in the usage levels of the Mashov system between parents of children in elementary school and parents of children in junior high was examined, and the second time the difference between parents of children in elementary school and parents of children in high school.

First test - t-test for independent samples - Examination of the difference in use of the Mashov system between parents of children in elementary school and parents of children in junior high: When examining the Levene's Test for equality of variances, the level of significance for reporting use of the Mashov system was found to be higher than $0.05(\mathrm{sig}=0.404)$, hence we received the null hypothesis whereby there is no difference between the parents in the variance values of using the Mashov system, and hence, no significant difference was found in use of the Mashov system between parents of children in elementary school and parents of children in junior high school.

Second test - t-test for independent samples - Examination of the difference in use of the Mashov system between parents of children in elementary school and parents of children in high school: When examining the Levene's test for equality of variances, the level of significance for reporting use of the Mashov system was found to be lower than 0.05 ( $\mathrm{sig}=0.044)$, hence we rejected the null hypothesis and received the $\mathrm{H}_{1}$ hypothesis whereby there is a difference between parents in the variance values of using the Mashov system, and a significant difference was found in use of the Mashov system between parents of children in elementary school and parents of children in high school.

In light of the above, a comparison was conducted between use of the Mashov system as reported by parents of children in elementary school and use reported by parents of children in high school, as detailed in Table 3 .

Table 3. Use of the Mashov System by Parents of Children in Elementary and High School

\begin{tabular}{lccc}
\hline \multicolumn{4}{c}{ Reported use of the Mashov system } \\
\hline Respondent group & No. of respondents & Mean & Standard deviation \\
\hline Parents of children in elementary school & 21 & 3.48 & 0.602 \\
Parents of children in high school & 58 & 3.62 & 0.489 \\
\hline
\end{tabular}

Looking at Table 3 above, it is evident that the mean use of the Mashov system by parents of children in high school is higher than the mean use of the Mashov system by parents of children in elementary school $\left(\right.$ Mean $_{\text {highschool }}>$ Mean $_{\text {elementary }}$ ). Therefore, parents of children in high school reported significantly greater use of the Mashov system than parents of children in elementary school. 


\section{Discussion}

The current study examined the effect of assimilating a learning management system, the Mashov system, on parent involvement in their children's educational process.

Examination of the first research hypothesis found that the higher the self-reported use of the learning management system by parents, the higher their self-reported sense of involvement in their children's education. Therefore, the first research hypothesis was confirmed. This corroborates a study conducted among 12 schools in UK (Selwyn, Banaji, Hadjithoma-Garstka, \& Clark, 2011), where the researchers sought to examine how the assimilation of learning management systems in a school might affect parent involvement in education. The research findings presented a fairly efficient process whereby the more the teaching staff chose to update the parents concerning their children by means of the learning management system (beginning from general updates on activities held at the school and ending with updates on the child's behavior and grades), the more the parents increased their use of the learning management system and took a more active part in the children's educational process.

Examination of the second research hypothesis found that parents reported better communication with the teaching staff the higher their self-reported use of the learning management system. Therefore, the second research hypothesis was confirmed. This corroborates a study conducted in the state of Utah in the US (Borup, Graham \& Davies, 2013), where the researchers sought to examine parents' level of involvement in their children's educational process and the factors influencing these levels of involvement. Moreover, the research procedure included thorough examination of communication between the teaching staff and the parents. The research findings indicated that the greater the displays of communication between the teaching staff and the parent, the greater the parents' involvement in the educational process, and vice versa. In that study, the researchers examined various interactions between the parents and the teaching staff, including written updates sent within the system, carried out in addition to face-to-face conversations and text messages exchanged between them.

Another example is provided by a study conducted in England (Head, 2020), whereby 15 mothers of school-aged children were interviewed concerning their trends of using the learning management system assimilated in the school. Analysis of the interviews found that the level of communication between the child's mother and the teacher was perceived as having high significance for the mothers and that through use of the digital learning systems available to them they felt that their communication with the teaching staff was maintained and even enhanced. Moreover, the researcher found that mothers' definition of a good level of communication with the teaching staff focused mainly on teachers' sharing information on their children's learning process, to which they would not have been exposed if not for the learning management system.

Moreover, a study that explored interactivity among students and their parents by means of the online Mashov system in Israel (Blau \& Hameiri, 2011) found that the readiness of the teaching staff to update the system regularly over time affects the access rate of the system by students and their parents and creates a new culture of online interaction between the school staff and the students and their parents.

Examination of the third research hypothesis found that although parents with children in high school reported higher use of the Mashov system than parents with children in elementary school, also parents with children in junior high did not report higher use of the Mashov system than parents with children in elementary school. Therefore, the third research hypothesis was only partially confirmed. This corroborates a study conducted in elementary schools in Indonesia (Sari, Zulaiha \& Mulyono, 2020), wherein the researchers sought to examine the effect of assimilating a digital learning management system on parents' level of involvement in education. The researchers, who as part of the research procedure followed usage trends of a digital learning management system by parents of elementary school aged children, found that the parents displayed use of the system, however not of all its potential applications. Then again, the researchers detected that unlike usage of the learning management system by parents with children in higher grades, at these ages parents provide their children with more emotional support and are less affected by the system's educational updates.

Another example is provided by a study conducted in a secondary school, which examined the effectiveness of the learning management system (Feldman, 2011). The research findings showed that parents' involvement in their children's educational work in secondary school has a proven impact on shaping their children's physical environment as well as on their achievements. Moreover, their involvement has a positive effect on the availability of the educational staff and encourages cooperation between them, and therefore the effectiveness of the learning management system is positively affected by the involvement of parents with children in secondary school. 


\section{Conclusion}

As of the present, modern research ascribes much significance to the problem of parent involvement in the process of teaching children, with the aim of improving its quality. Researchers believe that cooperation has a positive influence on students' learning and that the school and family together can achieve much more than individually (Christenson \& Sheridan, 2001). Studies on the factors blocking the success of studies in the US reform state that active collaboration between the family and the school is one of five factors that determine the success of any educational reform (Bryketal, 2010). Parent interest and involvement have a positive effect on classroom behavior, student motivation, self-evaluation, and the child's interest in the school. They also contribute to the moral development of the teachers and help the parents better understand their children (Hampden-Thompson \& Galindo, 2017).

It is evident that assimilation of a learning management system points to positive effects on parents' sense of involvement in their children's educational process as well as on encouraging communication channels between the parents and the teaching staff, when these intensify their use of it. The concept of parent involvement is expanding. It includes not only parent participation in management of the educational organization, working in bodies that take part in collegial shared management (for example, managing councils), rather any other activity, even "very modest", such as helping their children with homework. Parents are expressing interest and concern for their children's education. They want to be involved and to say what they can do at home to help their child do better at school.

Notably, we are in the midst of an unprecedented battle against the global coronavirus pandemic. Education enables governments, individuals, and families to build human capital, protect the poor and the vulnerable, and encourage economic recovery by promoting economic growth. A healthy educational policy must be the cornerstone of any response to a given crisis. The human capital accumulated in the world, which is one of the main sources of the nations' wealth, is at risk. The economic impact will be felt for many years. Schools are being closed around the world (Eyles et al., 2020) as part of the necessary steps for ensuring social distancing. This is affecting most school systems - a large number of children outside the school. In light of the above, the research procedure in this study was conducted in unusual times and during significant transformations experienced by the entire educational system in its efforts to faithfully serve the students who attend it during the year, under the challenges of social distancing and alternate lockdown conditions, including a lack of digital educational contents and good software for conveying lessons.

On one hand, there is no doubt that when the Mashov was first conceptualized, it was intended to serve as a traditional learning-support system conducted at the physical facilities of the schools, and to occupy a more secondary role than it came to occupy during the months of the study. Therefore, although the study has a considerable contribution in the context of the intensity in which the effects of assimilating the system during conduction of the study were examined, there is no question that these complex circumstances constituted an essential limitation of the study. Therefore, as a recommendation for further research, the current study should also be held when the normal routine is resumed, as the management of digital educational data has become an inseparable part of practices utilized by schools, since access to the school database, whether by teachers, students, or parents, via mobile devices, has been proven to promote educationally-based interactions among all those involved in the process.

\section{Acknowledgments}

The authors wish to thank Anna Sharabi Blanki, undergraduate student of social sciences at Ariel University, for their assistance in data collection for this study.

\section{References}

Blau, I., \& Hameiri, M. (2011). Online parental involvement in the $21^{\text {st }}$ century: Students and parents using the Mashov learning management system. Open University.

Blau, I., \& Hameiri, M. (2012). Teachers, students, and their parents in assimilation of technological change: The Mashov learning management system. Dapim, 54, 105-138. [in Hebrew]

Borup, J., Graham, C. R., \& Davies, R. S. (2013). The nature of parental interactions in an online charter school. American Journal of Distance Education, 27, 40-55. https://doi.org/10.1080/08923647.2013.754271

Cameron, L., \& Mahoney, K. (2008). Introducing a Learning Management System (LMS) into your school: Some considerations. In: J. Luca \& E. R. Weippl (Eds.), Proceedings of World Conference on Educational 
Multimedia, Hypermedia and Telecommunications (pp. 2826-2831).

Christenson, S. L., \& Sheridan, S. M. (2001). School and families: Creating essential connections for learning. New York, NY: Guilford Press.

Davidovich, N., \& Yavich, R. (2015). Technology-related involvement: The effect of the MASHOV system on parent involvement in Israeli junior highs. Journal of International Education Research; Littleton, 11(4), 243-252. https://doi.org/10.19030/jier.v11i4.9458

Davidovich, N., \& Yavich, R. (2017). Who needs parent-teacher meetings in the technological era? International Journal of Higher Education, 6(1), 153-162. https://doi.org/10.5430/ijhe.v6n1p153

Eyles, A., Gibbons, S., \& Montebruno, P. (2020). COVID-19 school shutdowns: What will they do to our children's education? London School of Economics and Political Science: A CEP COVID-19 analysis Paper No. 001. 2020.

Feldman, H. (2011). The role of a technological tool for pedagogic management in homeroom teachers' effective management of their classrooms in secondary schools. Oranim - Academic College of Education. [in Hebrew]

Forkosh-Baruch, A., Nachmias, R., Mioduser, D., \& Tubin, D. (2005). Islands of innovation and school-wide implementation: Two patterns of ICT-based pedagogical innovations in schools. Human Technology, 1(2), 202-215. https://doi.org/10.17011/ht/urn.2005358

Hampden-Thompson, G., \& Galindo, C. (2017). School-family relationships, school satisfaction and the academic achievement of young people, Educational Review, 69(2), 248-265. https://doi.org/10.1080/00131911.2016.1207613

Hango, D. (2007). Parental investment in childhood and educational qualifications: Can greater parental involvement mediate the effects of socioeconomic disadvantage? Social Science Research, 36, 1371-1390. https://doi.org/10.1016/j.ssresearch.2007.01.005

Head, E. (2020). Digital technologies and parental involvement in education: The experiences of mothers of primary-school-aged children. British Journal of Sociology of Education, 41(5), 593-607. https://doi.org/10.1080/01425692.2020.1776594

Hoover-Dempsey, K. V., Whitaker, M. C., \& Ice, C. L. (2010). Motivation and commitment to family-school partnerships. In S. L. Christenson \& A. L. Reschly (Eds.), Handbook of school-family partnerships (pp. 30-60). New York: Routledge.

Kaplan Toren, N. (2004). Parent involvement, self-evaluation, and student achievements in junior high school (PhD Dissertation). Haifa University. [in Hebrew]

Maciariello J. A. (2018). Drucker, Peter: The Drucker Strategic Management System. In: Augier M., Teece D.J. (Eds.), The Palgrave Encyclopedia of Strategic Management. Palgrave Macmillan, London. https://doi.org/10.1057/978-1-137-00772-8_629

Neal, R. B. (2012). Checking in or checking out? Investigating the parent involvement reactive hypothesis. The Journal of Educational Research, 105, 79-89. https://doi.org/10.1080/00220671.2010.519410

Rogers, E. M. (1995). Elements of diffusion. In E. M. Rogers, Diffusion of innovations (4th ed.) (pp. 1-37). New York: The Free Press.

Sari, Y. Y., Zulaiha, S., \& Mulyono, H. (2020). The development of a digital application to promote parents' involvement in character education at primary schools. Elementary Education Online, 19(4), 2564-2570.

Selwyn, N., Banaji, S., Hadjithoma-Garstka, C., \& Clark, W. (2011). Providing a platform for parents? Exploring the nature of parental engagement with school learning platforms. Journal of Computer Assisted Learning, 27, 314-323. https://doi.org/10.1111/j.1365-2729.2011.00428.x

Shechtman, Z., \& Bushrian, O. (2015). Between parents and teachers in secondary education: State of affairs and recommendations. Israel Academy of Science - Initiative for Applied Research in Education. [in Hebrew]

Timan, M. (2007). Assimilation of Mashov software use at the "Ohel Shem" high school in Ramat Gan: Teachers' attitudes towards the effect of utilizing the software, advantages and difficulties in assimilation of the software. Final paper for MA in social sciences, Tel Aviv University, School of Education. [in Hebrew]

Yavich, R. (2013). Social networks and students. Research Journal of Management Sciences, 2(2), 1-2. 


\section{Copyrights}

Copyright for this article is retained by the author(s), with first publication rights granted to the journal.

This is an open-access article distributed under the terms and conditions of the Creative Commons Attribution license (http://creativecommons.org/licenses/by/4.0/). 